\title{
Eliminating early cut-offs and estimating cycle end time in a tumble dryer
}

\author{
Luke Fullard ${ }^{1} \quad$ Winston L. Sweatman ${ }^{2} \quad$ Matt Wilkins $^{3}$
}

(Received 28 January 2016; revised 14 December 2016)

\begin{abstract}
Modern domestic clothes dryers contain sensors which attempt to detect when the load is dry, and subsequently, when the drying process should be ceased. However, due to a range of factors, occasionally the dryer may cut-off earlier than is desired. At a recent mathematics-inindustry study group workshop in New Zealand (MINZ-2015), Fisher and Paykel presented the challenge of eliminating these early cut-offs. Using a statistical fitting technique which accounts for stochastic noise and utilises confidence intervals, we outline a more rigorous procedure
\end{abstract}

DOI:10.21914/anziamj.v57i0.10523, (c) Austral. Mathematical Soc. 2016. Published December 30, 2016, as part of the Proceedings of the 2015 Mathematics and Statistics in Industry NZ Study Group. ISSN 1445-8810. (Print two pages per sheet of paper.) Copies of this article must not be made otherwise available on the internet; instead link directly to the DOI for this article. Record comments on this article via http://journal . austms . org. au/ojs/index.php/ANZIAMJ/comment/add/10523/0 
for detecting the end state of the drying process. We analyse experimental data provided at the workshop and investigate the possibility of estimating drying cycle end time in advance. Finally we interrogate the experimental data to estimate physical drying parameters which may be used in a reaction engineering drying model.

\section{Contents}

1 Introduction

2 Estimating cut-off time based on regression models $\quad$ M240 2.1 Introduction and problem . . . . . . . . . . . M240

2.2 Proposed solution . . . . . . . . . . . . . . . . M242

2.3 Residuals, implementation and termination policy . . . . M245

2.4 Summary . . . . . . . . . . . . . . . . M248

3 Estimation of Load Mass $\quad$ M249 3.1 Attempts to fit load mass . . . . . . . . . . . M250 3.2 Fourth order polynomial fit . . . . . . . . . . M250

4 Estimation of model parameters $\quad$ M257 4.1 Experimental determination of the activation energy for a cotton load . . . . . . . . . . . . . M260

5 Discussion and conclusions $\quad$ M263

References 


\section{Introduction}

Fisher and Paykel have a long history of providing interesting projects to mathematicians in New Zealand. For example in the earlier mathematics-inindustry study groups in New Zealand, Fisher and Paykel brought projects on washing machine temperature control [1] and washing machine dynamics [2]. Fisher and Paykel continue to develop new technology, and the present project concerns their advancements in clothes dryers for domestic use. The project presented at MINZ-2015 concerned improving end-cycle identification, and better understanding the drying process for various load weights and types (cotton, mixed, for example). New dryers use a thermistor to measure the exhaust temperature throughout the drying cycle. In the simplest control method the dryer switches off once a temperature threshold is exceeded. The temperature threshold was determined experimentally (by Fisher and Paykel) and depends on the load type, the mass of the clothes, and the desired dryness level. However, the exhaust temperature is a noisy signal. This is due to variations caused by the tumbling and bunching of the clothes, among other factors. As the measurement fluctuates it may exceed the threshold before the clothes are completely dry, leading to a false positive, and an early cessation of the drying process. During dryer testing, Fisher and Paykel performed many experiments with various load types and masses resulting in a large number of temperature curves. The majority of the temperature curves have a similar shape regardless of load size and load type. For all experimental conditions, these curves look approximately cubic in shape, and demonstrate similar characteristic behaviour:

- a warm-up phase where the exhaust temperature rises quickly;

- a steady pre-critical phase where the rate of change in temperature is relatively modest and linear;

- a critical state where the rate of drying (loss of water mass) decreases rapidly leading to a steep increase in the exhaust temperature. 
Figure 1 shows typical temperature data.

The MINZ group was tasked with developing a method to better analyse the temperature measurements to avoid false cut-offs, and to study the experimental data to better understand the drying process in the machine and to ascertain if there was any further information that could be used within the experimental measurements. Since the machines have only a small amount of processing power and RAM, any solution to the cut-off detection problem should be computationally modest and straightforward to implement. This report details the approach used to better estimate the cut-off time in Section 2, while Section 3 presents analysis of the data relating to estimating the time still remaining in the drying process, along with other observations. Finally, in Section 4, we use the provided experimental data to estimate necessary physical parameters for a reaction engineering based mathematical model.

\section{Estimating cut-off time based on regression models}

\subsection{Introduction and problem}

Using a simple temperature threshold in domestic clothes dryers to detect end-cycle is error prone and may produce early cut-offs. The dryer is unable to directly measure the moisture content of the clothes, hence correct cut-off time must rely on some indirect measure. In the present section we consider this to be the temperature difference between the drier inlet air and outlet air, $\Delta \mathrm{T}$. This corresponds to just outlet temperature in constant ambient temperature surroundings. We assume that from theoretical and empirical considerations we may find an ideal cut-off temperature value, $\Delta \mathrm{T}_{0}$. Currently, the dryer will terminate when $\Delta \mathrm{T}=\Delta \mathrm{T}_{0}$. However, due to bunching of the clothes and other factors the exhaust outlet temperature fluctuates, at 
Figure 1: The temperature difference between the inlet air and the outlet air of the drier $\Delta T(t, m)$ for three different masses of cotton clothing, $6 \mathrm{~kg}$ (top), $2 \mathrm{~kg}$ and $0.8 \mathrm{~kg}$, as measured by experimental runs. The coloured lines correspond to the cut-off temperatures for the given load: red being for extra dry, dark-green for regular dry and blue for damp dry.
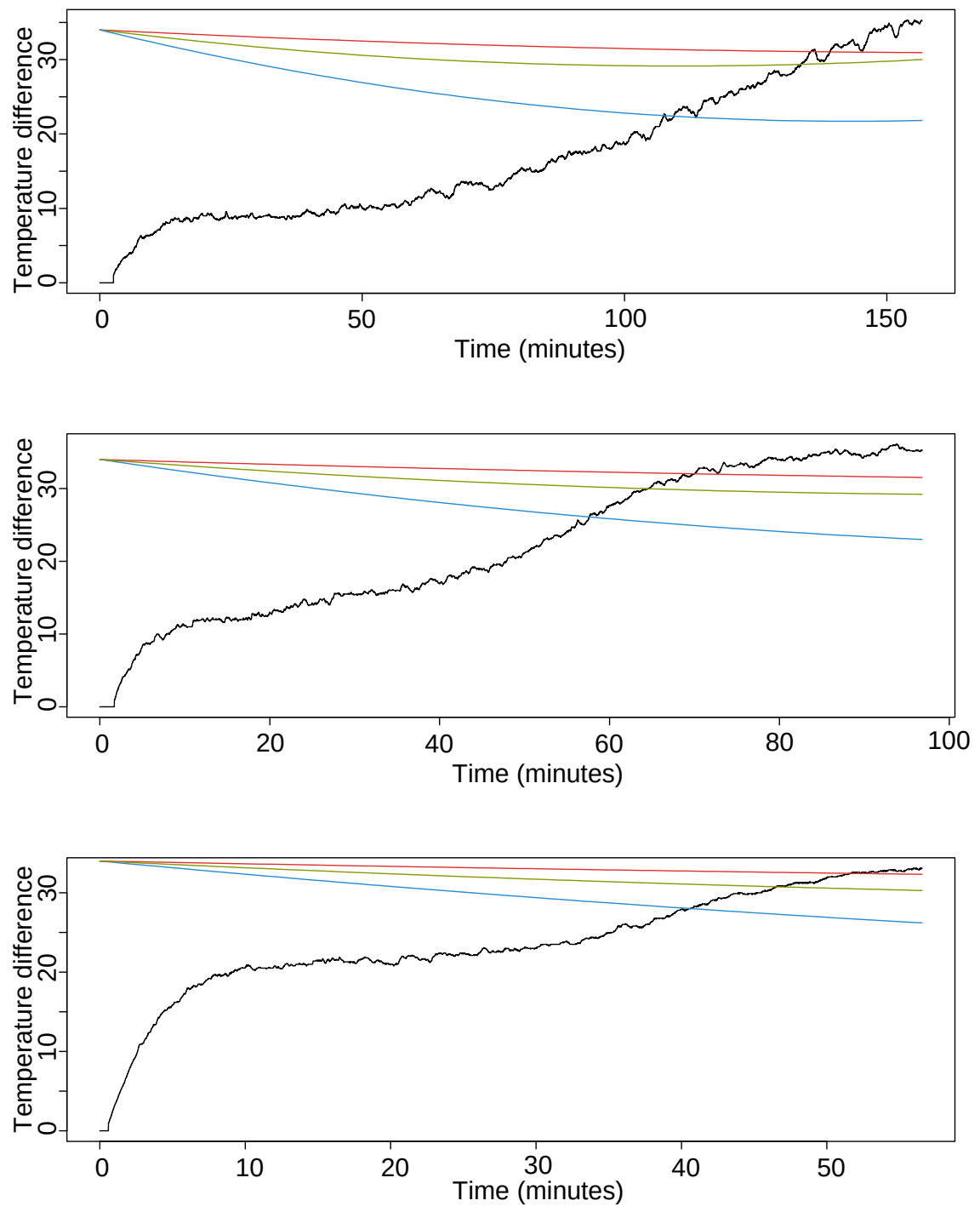
times this fluctuation creates a spike in the temperature difference which exceeds $\Delta \mathrm{T}_{0}$. The measurement then may drop below $\Delta \mathrm{T}_{0}$ as the clothes un-bunch. Terminating as soon as the temperature exceeds $\Delta \mathrm{T}_{0}$ may lead to the cycle finishing prematurely with clothes at a less than ideal dryness.

There is a steady modest increase in inlet (ambient) temperatures in the experimental data. This is much smaller than the increase in outlet temperature. The effect is due to the drier having a heating effect on the constrained area where the experiments took place.

One solution to the premature cut-off is to simply run the dryer for a few more minutes after the temperature has reached its target. However, as well as being an inefficient solution, over-drying is possible, and the number of minutes which need to be added varies depending on the (unknown) mass of the clothes.

\subsection{Proposed solution}

Our proposed solution relies on using a regression model to decompose the temperature readings into a deterministic part and a 'stochastic noise' part. In general suppose we have some physical process governing $\Delta T(t, m)$, dependent on time $t$ and some other parameter $m$ (in our case mass). Further suppose that

$$
\Delta T(t, m)=M(t, m)+X(t, m),
$$

where $M(t, m)$ is a deterministic function relating to the moisture content of the clothes and $X(t, m)$ is stochastic noise due to bunching of the clothes and other effects. Our knowledge of $M(t, m), X(t, m)$ and $m$ are limited; the dryer only measures $\Delta T(t, m)$ as a function of time, $t$. When $\Delta T$ exceeds the target $\Delta \mathrm{T}_{0}$, we must discern if this was due to the deterministic function $M(t, m)$ or the stochastic noise. That is, does the temperature difference, $\Delta T(t, m)$, exceed the target $\Delta T_{0}$ because the moisture content of the clothes is low enough, or because of stochastic noise (for instance, due to bunching of clothes). 
Our approach is to take a regression model $N(t, m)$ to estimate $M(t, m)$. If the form of the function $\mathrm{N}(\mathrm{t}, \mathrm{m})$ is known from physical models, then it can be used. However, since we do not have a reliable physical model, polynomial/spline regression is used. We assume that the residues of the regression model (the difference between the regression model $\mathrm{N}(\mathrm{t}, \mathrm{m})$ and the actual observed value $\Delta T(t, m)$ at that time), approximate the stochastic noise $X(t, m)$. Analysis indicates it is reasonable to assume the stochastic term, $X(t, m)$, is stationary with respect to time in the period when approaching target temperature. In this case the approximation of the stochastic noise will give an estimation of how likely it is that $\Delta T=\Delta T_{0}$ is due to the deterministic part, $M(t, m)$, or due to the stochastic noise, $X(t, m)$, itself. Therefore, we use the residues to construct a 'band of error' of one to two standard deviations about the regression curve. Anything that falls inside this band is quite plausibly explained by the stochastic noise. ${ }^{1}$

Figure 1 presents a sample of raw data for three different masses, $6 \mathrm{~kg}, 2 \mathrm{~kg}$ and $0.8 \mathrm{~kg}$, for a cotton wash. The temperature difference, $\mathrm{T}(\mathrm{t}, \mathrm{m})$, is the difference between the inlet air and the outlet air, and is measured by the dryer. The three coloured curves represent the cut-off temperatures which are selected on the dryer by the user: red being for extra dry; dark-green for regular dry; and blue for damp dry. The ideal cut off times for the dryer are found using an earlier second-order regression model provided by Fisher and Paykel. This has a slight negative correlation between the temperature difference and time, so that the target cut-off temperature is not constant which results in the sloped cut-off lines shown in the figure.

Three observations are made from the plots. First, as may be expected, a change of load mass significantly alters the temperature curve. Secondly, the variance does not appear to be constant throughout the drying process, and thirdly, the variance is dependent on the mass of the load (it seems to increase substantially for the $6 \mathrm{~kg}$ load). The latter two observations are at this stage purely heuristic, to accurately analyse the variance we need to compare it

${ }^{1}$ Strictly speaking this depends on the distribution of the stochastic noise. From the experimental data it appears appropriate in this case (cf. Subsection 2.3). 
against a regression model.

For each load the first period of the drying process is characterised by a distinctive steep ascent with very little variance. Whilst perhaps interesting for development and testing of deterministic mathematical models, this part of the drying period serves only to distort our regression model and our estimation of variance. Therefore we truncate the data by the first 1220 data points, which correspond to approximately the first ten minutes of data, and so remove this part when considering the variance near the cut-off.

Given this truncation, we use the remaining data to construct a regression model. The dryer will only have the data up to the target temperature and we are not fitting a regression model for the whole process. The two essential things that this approach requires are that the regression model is locally a good predictor of the deterministic function, and we have a good estimate of the variance of $X(t, m)$.

Given this emphasise on locality, a logical approach is to only use the most recent part of the data in the regression model. A practical way to do this is to just consider the last $n$-percent of the data.

In the target temperature regions, a linear model is a reasonable approximation to the data. That is, fitting a straight line through the most recent part of the data, seems to have good predictive power. Straight lines also have the advantage of being simple, robust, and unlikely to diverge too rapidly from $M(t, m)$. (A parabola may also be a suitable alternative.) The predictive power of linear regression models seems to be most at risk at the higher target temperatures and the lower masses where the data plateaus out. However, we take some solace in that our approach with the simple linear regression is biased towards terminating the drying process later rather than earlier, which is the preferable kind of bias.

The local regression model should capture the variance. Linear regression models were fitted at several points across various samples to see how the residuals were distributed. These suggest a fairly robust and reliable approx- 
imation. Nonetheless, the potential risk of loss of predicative power of the linear regression at some high temperatures naturally causes concern that the residues are going to be less reflective of the stochastic noise. An alternative is to take a one size fits all approach and simply apply one band of error to all regression models. Alternatively, for a larger computational cost, a local polynomial regression model could be computed, as well as the linear fit, throughout the whole data (except the truncated initial steep rise) as opposed to simply around the target temperatures. This provides a better global fit and more accurately captures the variance. This estimation of variance would then be used, along with the local regression model, to formulate the bands of error and termination policy. ${ }^{2}$

Figure 2 illustrates these ideas. A local second-order polynomial fit has been made with confidence bands of \pm 1.5 standard deviations. The fitted data excludes the first ten minutes and stops at $\Delta \mathrm{T}=30^{\circ} \mathrm{C}$ which corresponds to approximately the target temperature difference.

\subsection{Residuals, implementation and termination policy}

Given our approach outlined in the previous subsection, we now discuss a possible termination policy and consider how much of the stochastic noise will fall within the error bands. To obtain a better understanding we need to investigate the distribution of the residuals of the local polynomial regression model. Figure 3 shows the local polynomial regression plots from the end of the first ten minutes until the temperature difference is $30^{\circ} \mathrm{C}$ (at approximately the target temperature). A density plot of the residuals, which is our estimation of the stochastic noise, is given alongside.

One observes the remarkable similarity between the polynomial fitting of these data sets over this range. The residuals exhibit minor differences between the different loads. We have used the empirical estimate that, for these data sets,

${ }^{2}$ Although it will fit a nice curve through the data, unfortunately it is a little harder to use for predictive power. 
Figure 2: Raw temperature data over time for a $2 \mathrm{~kg}$ washing load. In red is a second-order polynomial fit, and the two smooth purple lines are the upper and lower confidence intervals at \pm 1.5 standard deviations.

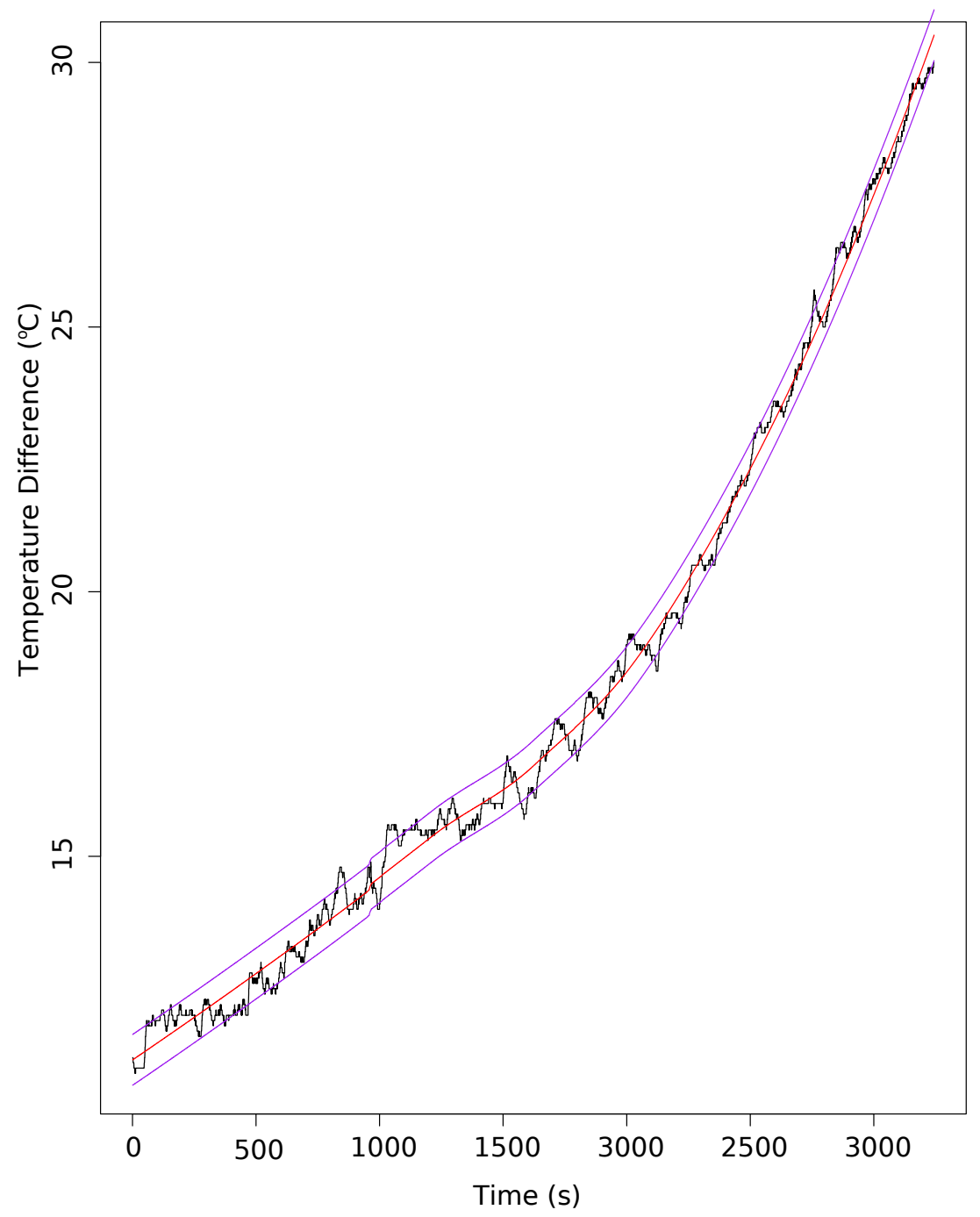


Figure 3: Left: The raw data temperature differences (black) and the polynomial fit (red). Right: The distribution of the residuals (the difference between the temperature differences and fit). The order from top to bottom is the $6 \mathrm{~kg}$ data set, the $2 \mathrm{~kg}$ data set and then the $0.8 \mathrm{~kg}$ data set.
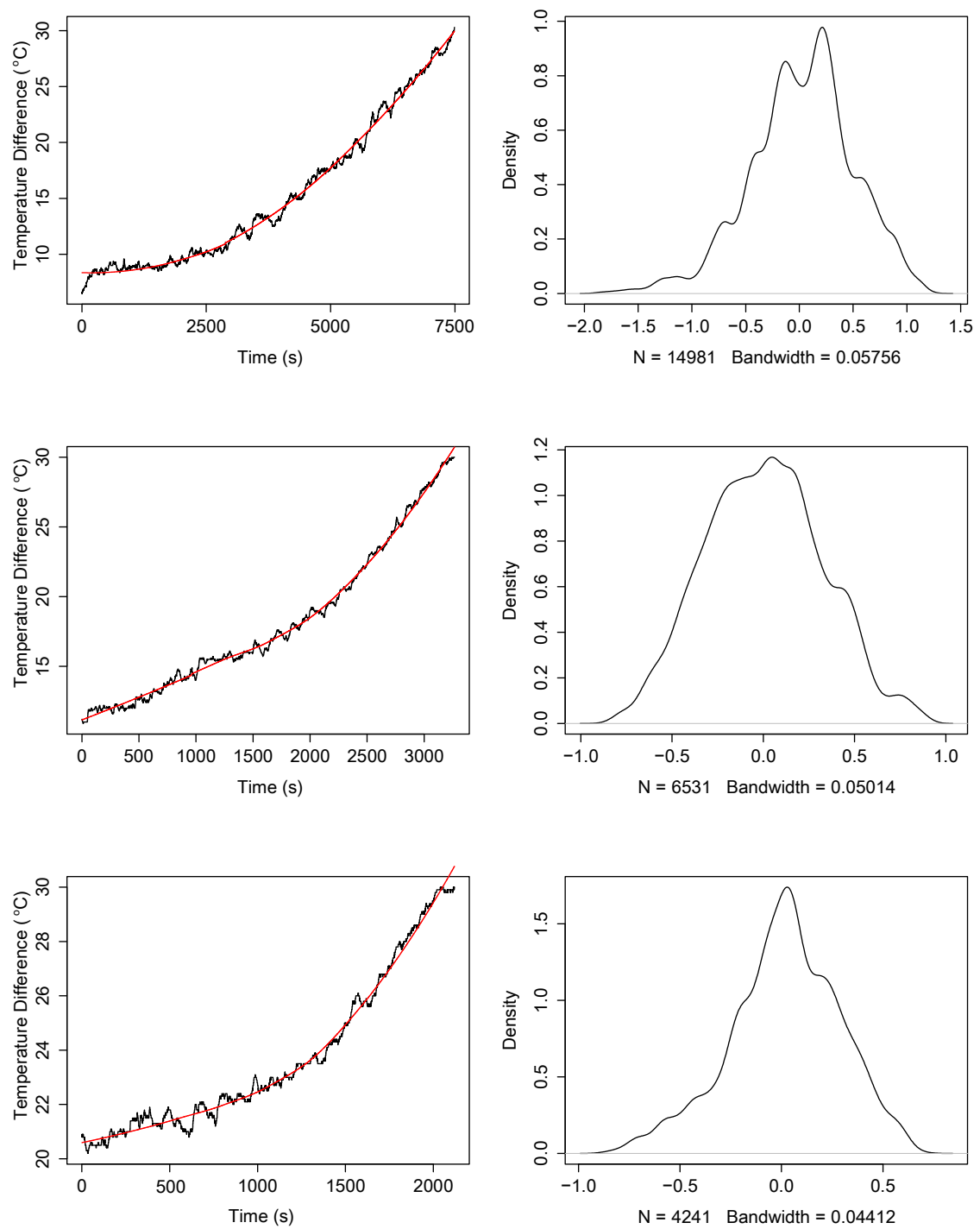
a confidence band of \pm 1.5 standard deviations captures at least $85 \%$ of the residuals and a confidence band of \pm 2 standard deviations captures $94 \%$ of them.

We therefore propose the following termination policy. Terminate the drying process if both the following conditions are met:

- the current temperature difference is above the target temperature difference; and

- the lower confidence estimate exceeds the target temperature difference.

By using a band of width \pm 1.5 standard deviations, we estimate that the dryer will not prematurely terminate at least $85 \%$ of the time.

\subsection{Summary}

We summarize our main points as follows.

- The method proposed allows for the stochastic noise (due to bunching of the clothes) within the measured outlet temperature. If a band of \pm 1.5 standard deviations is used, then we estimate that the dryer will not prematurely terminate at least $85 \%$ of the time.

- Although we have presented what, in our preliminary opinion, is the best choice of regression, there are many parameters to this approach that can be changed. For instance, the regression model may be changed based upon further development of deterministic mathematical models, further experimental evidence, or simply practical considerations. These parameters include, but are not limited to, local regression model, methods to estimate variance, data truncation, band of error, and the termination policy.

- In particular, we suggested either using local linear or parabolic regression in the period leading up to the target temperature (Subsection 2.2). 
Whatever is chosen, we recommend maintaining a level of simplicity, since it is desired that the method work for a variety of curves.

- The accuracy of this method relies on the stochastic error term being approximately constant in time (at least in the period of interest), and the process not being so non-linear that local regression models around the period of interest have no predicative power. Figure 3 suggests the hypothesis that the process is stationary is a reasonable assumption.

\section{Estimation of Load Mass}

The approach of Section 2 is used to fit regression models to experimental data for each set of parameters. One key parameter is load size or total mass of the load. This parameter is further subdivided into the dry mass of the clothes and the mass of the water content within the clothes. The clothes dryer does not measure this mass directly. As such, attempts were made to devise a method to estimate this load mass from the data available to the clothes dryer.

Various approaches were tried to obtain the load mass, including attempts to condense the temperature curves using load mass, and estimation using the slope of the linear regions of the temperature curve. However, it was ultimately found that fitting a fourth order polynomial to the temperature data and then determining the first point of inflection of this polynomial produced a consistent state of the system for a given load type. If this load state were to be experimentally determined for given load types, then we believe that this method could be used to estimate the total load size as well as the percentage of moisture content remaining in the clothes. 


\subsection{Attempts to fit load mass}

While testing, Fisher and Paykel collected experimental data with simultaneous measurement of the temperature and the total mass of the dryer and clothes. As the drying cycle progresses, the mass lost corresponds to the mass of water evaporated. During the main part of the drying cycle, water removal occurs at an almost constant rate independent of mass. Figure 4 illustrates this relationship for various masses of cotton laundry. We interpret this as the air being fully saturated with water vapour after passing through the clothes. At the end of the cycle the drying rate reduces.

\subsection{Fourth order polynomial fit}

The points of inflection of the temperature curve may provide an estimate of the load mass, using the experimental observations related to the moisture content and drying rate. In order to determine these points of inflection, a fourth order polynomial was fitted to the temperature data using a least squares algorithm. The first point of inflection was determined from this polynomial fit. Figures 5 and 6 show the results.

The polynomial was fitted to all the data (the steep ascent period was not excluded). A fourth-order polynomial was used as the temperature curve is believed to have two points of inflection and a fourth-order polynomial is the simplest function that could have this property. With this choice it is also easy to differentiate and determine these points of inflection.

By matching the time at which the first point of inflection occurs with the corresponding time in the percentage moisture content curve, we found that the first point of inflection occurs at approximately the same point in the moisture curve for all load sizes for a given load type. In the examples given in Figures 5 and 6 , this was a percentage moisture content of approximately $30 \%$ for a cotton load and $25 \%$ for a realistic mixed load. Fits were also made 
Figure 4: Mass of water lost against time for different masses of cotton clothes

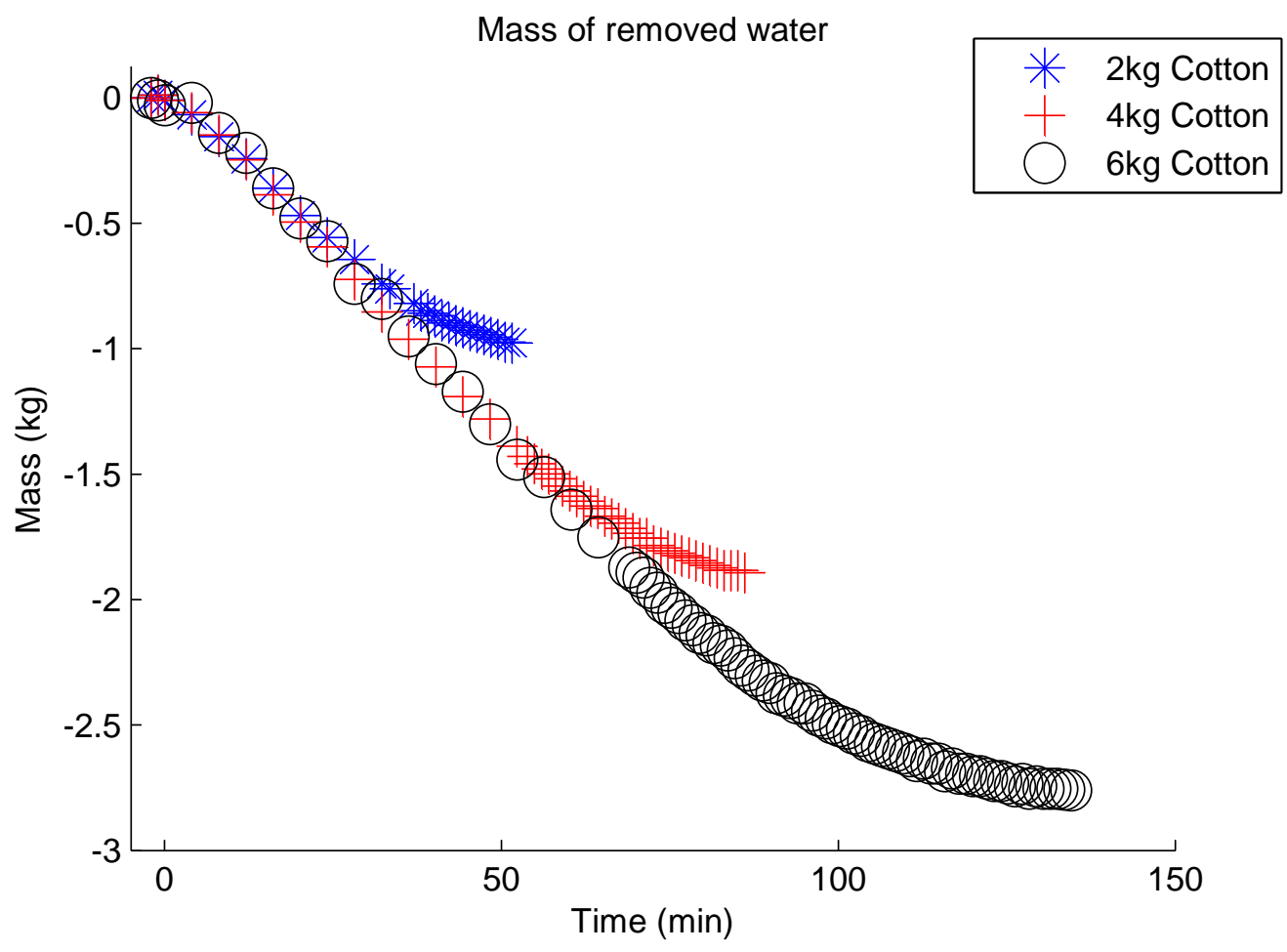

for different machines for the same load types (cotton and real) with similar results.

Therefore it appears possible to estimate the percentage of water remaining in the clothes. Furthermore, by measuring the time to reach the point of inflection, it should be possible to infer the mass of the load and the time remaining in the drying cycle. This method requires further experimental analysis in order to ascertain the state of the system at the point of inflection for a given load type. 
Figure 5: Temperature and moisture content curves for Machine \#36 with a cotton load and everyday high heat setting. The solid line is associated with the temperature axis on the left and corresponds to the fitted fourth order polynomial. The thin dashed line underneath corresponds to the experimental temperature data. The thicker dashed line corresponds to the percentage of water content left in the clothes and is associated with the axis on the right. The circle corresponds to the first point of inflection on the fitted polynomial and the cross is the percentage moisture content at this inflection time.

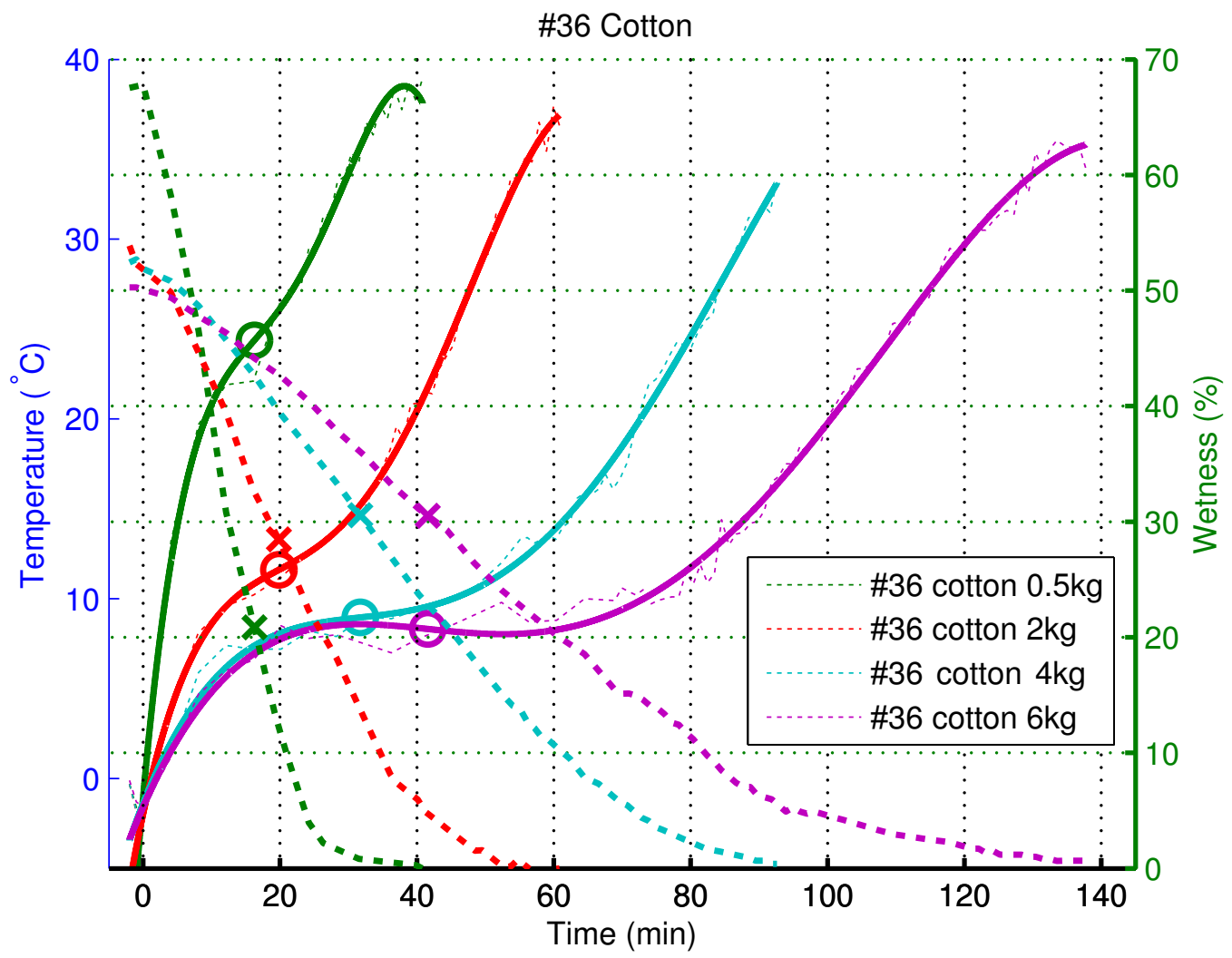


Figure 6: Temperature and moisture content curves for Machine \#39 with a realistic mixed load and the everyday high heat setting. As in Figure 5, the solid line is associated with the temperature axis on the left and corresponds to the fitted fourth order polynomial. The thin dashed line underneath corresponds to the experimental temperature data. The thicker dashed line corresponds to the percentage of water content left in the clothes and is associated with the axis on the right. The circle corresponds to the first point of inflection on the fitted polynomial and the cross is the percentage moisture content at this inflection time.

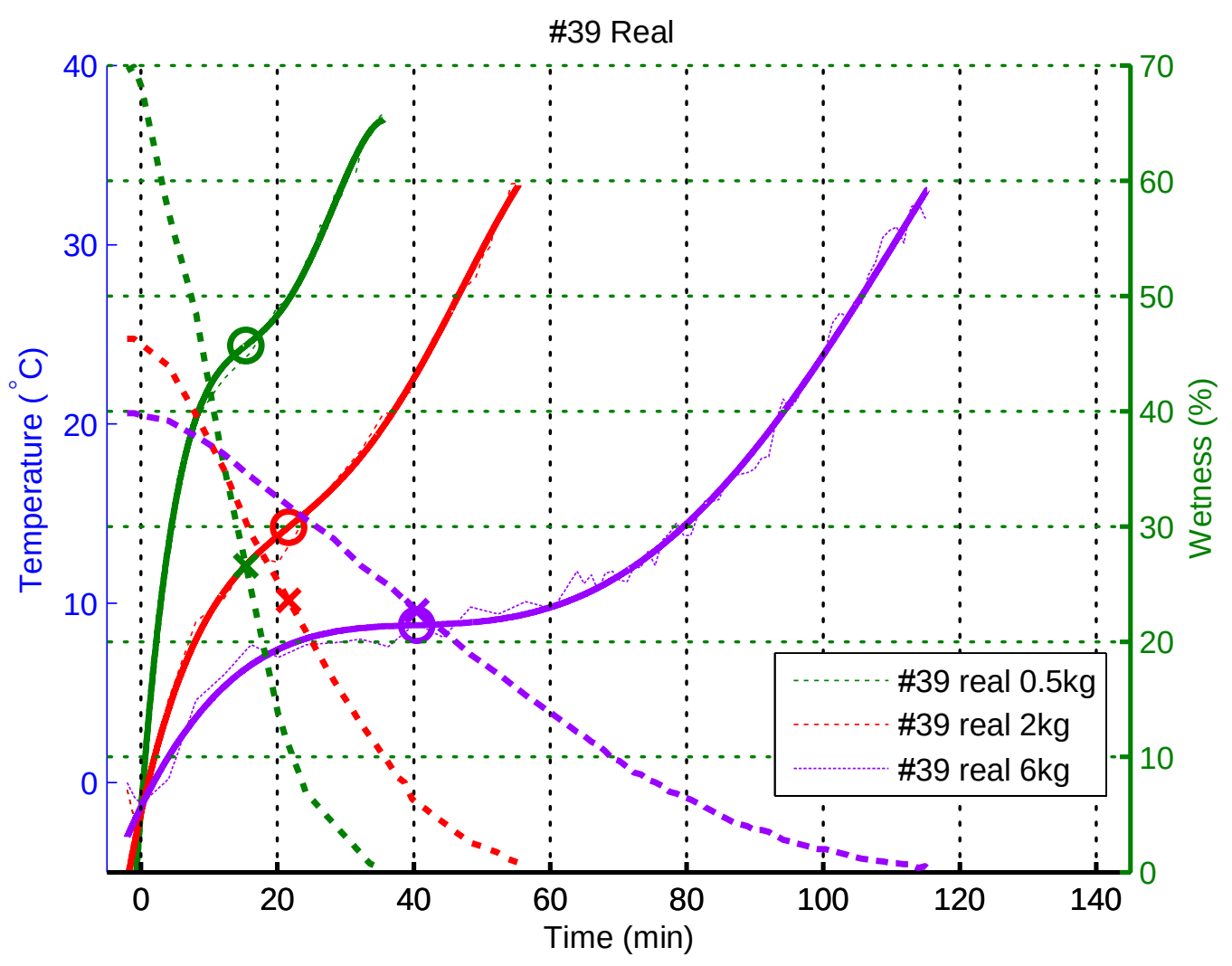


Another question that arises is whether it is possible to accurately determine this point of inflection while the machine is running and without the complete set of temperature data. To determine whether this is possible, the polynomial was fitted to the temperature data adding one point at a time to obtain a local polynomial fit (the fitted function could be similar to that used for the stochastic model of Section 2). The resulting curves are presented in Figures 7 and 8. (These plots use different data than Figures 5 and 6.)

In Figures 7 and 8, sub-figure (a) shows the actual temperature and moisture data, along with the polynomial fitting. Sub-figure (b) displays the predicted wetness values as more data is added over time. Similarly, sub-figure (c) in Figures 7 and 8 displays the predicted inflection times as more data are added over time. The wetness values in (b) are only available when the predicted inflection time from (c) is positive, hence the curves appear disjointed. Clearly, negative inflection times are not physically realistic. Their occurrence implies that there is insufficient data to accurately predict the moisture content and inflection times at this stage in the drying cycle. It is not possible to accurately determine the inflection point until after the machine has been running for some time after the temperature inflection has occurred. However, for all loads except the smallest $0.5 \mathrm{~kg}$ load, the inflection point is determined at least 15 minutes before the end point. In the case of the smallest load, the current inflection point is only determined a few minutes before the end of the drying cycle. It may still be possible to detect this inflection point from the behaviour of the estimate. Alternatively, it may be possible to obtain a faster estimate of the inflection time by using some kind of constrained polynomial or a more sophisticated fitting algorithm. If these methods prove to be infeasible, then a different method may be required to handle the case of very small loads. One possibility is a method involving a cut-off temperature.

Knowledge of the time of inflection may allow the state of the system to be determined dynamically, and may, with further experimental investigations, be used to estimate the time remaining in the drying process. This is a topic of further study. 
Figure 7: Results from the data for a realistic mixed load type on machine \#36 with the everyday high heat setting. (a) Temperature and percentage moisture content, as in Figure 5. (b) The predicted percentage moisture content using measurement data prior to the time given on the horizontal axis. (c) The corresponding predicted inflection time using measurement data prior to the given time.

(a)

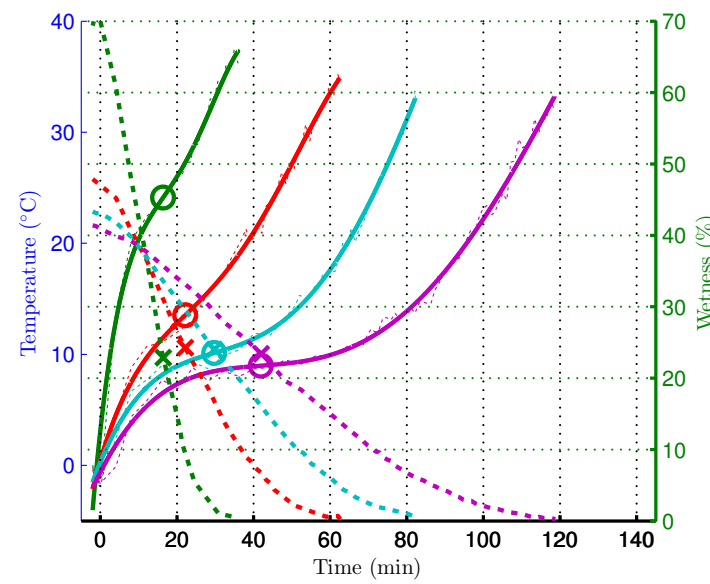

(c)

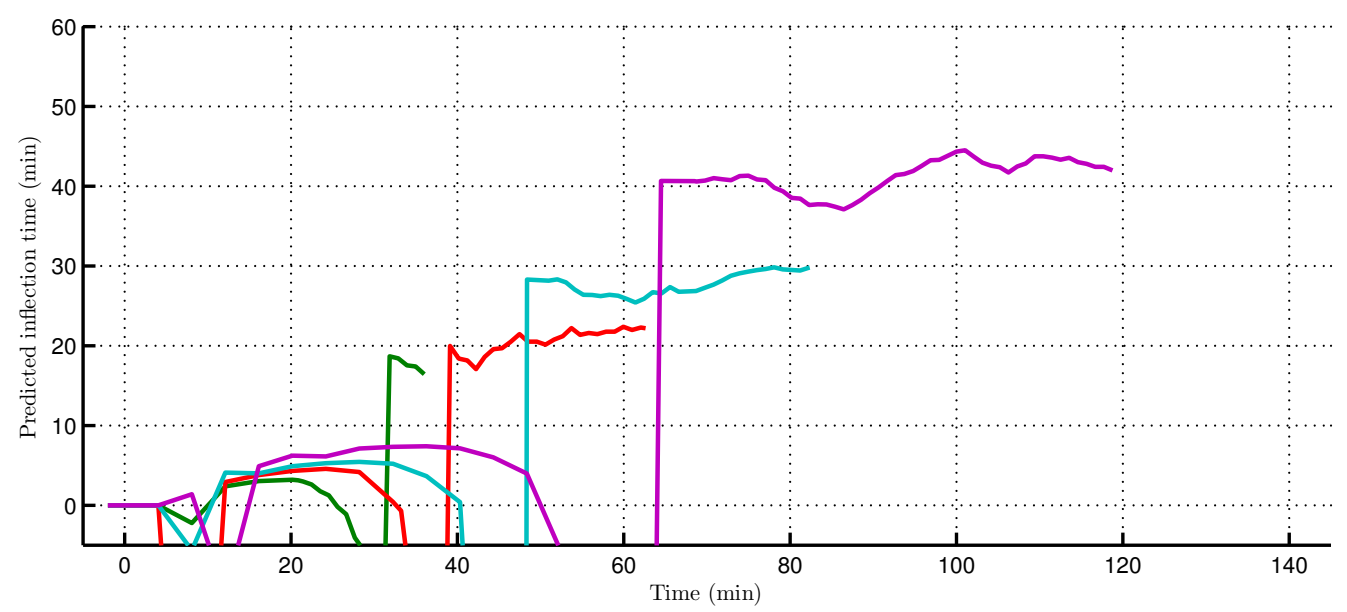

(b)

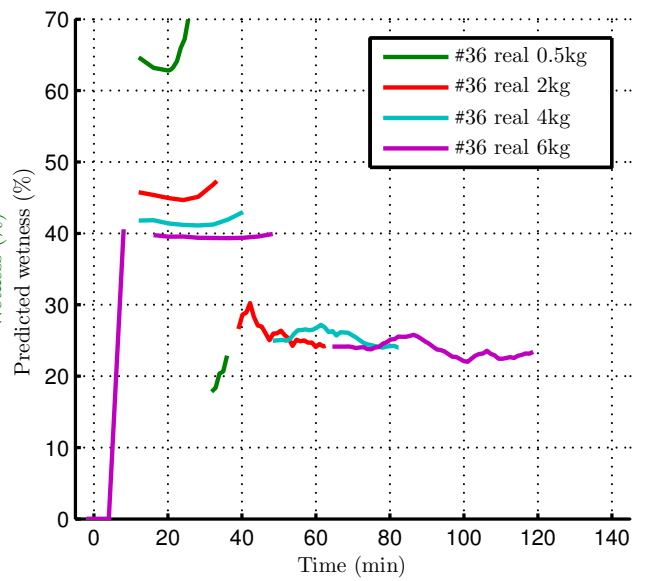


Figure 8: Results from the data for a cotton load type on machine \#39 with the everyday high heat setting. (a) Temperature and percentage moisture content, as in Figure 5. (b) The predicted percentage moisture content using measurement data prior to the time given on the horizontal axis. (c) The predicted inflection time using data up to the given time.

(a)

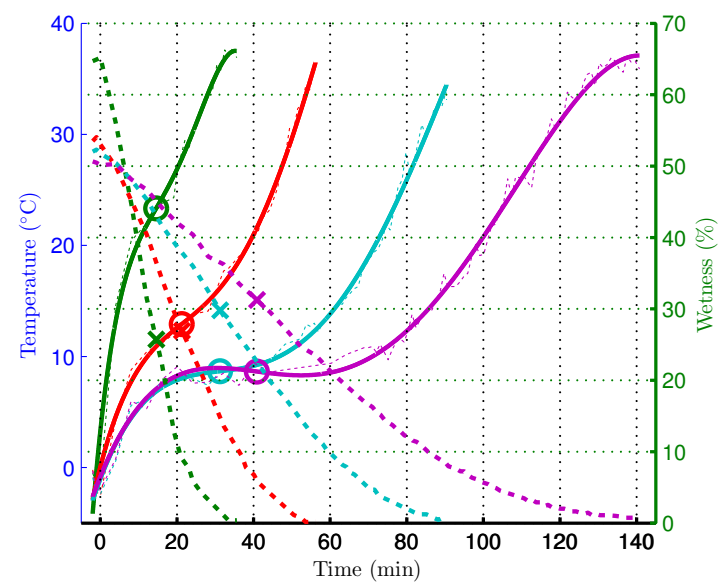

(c)

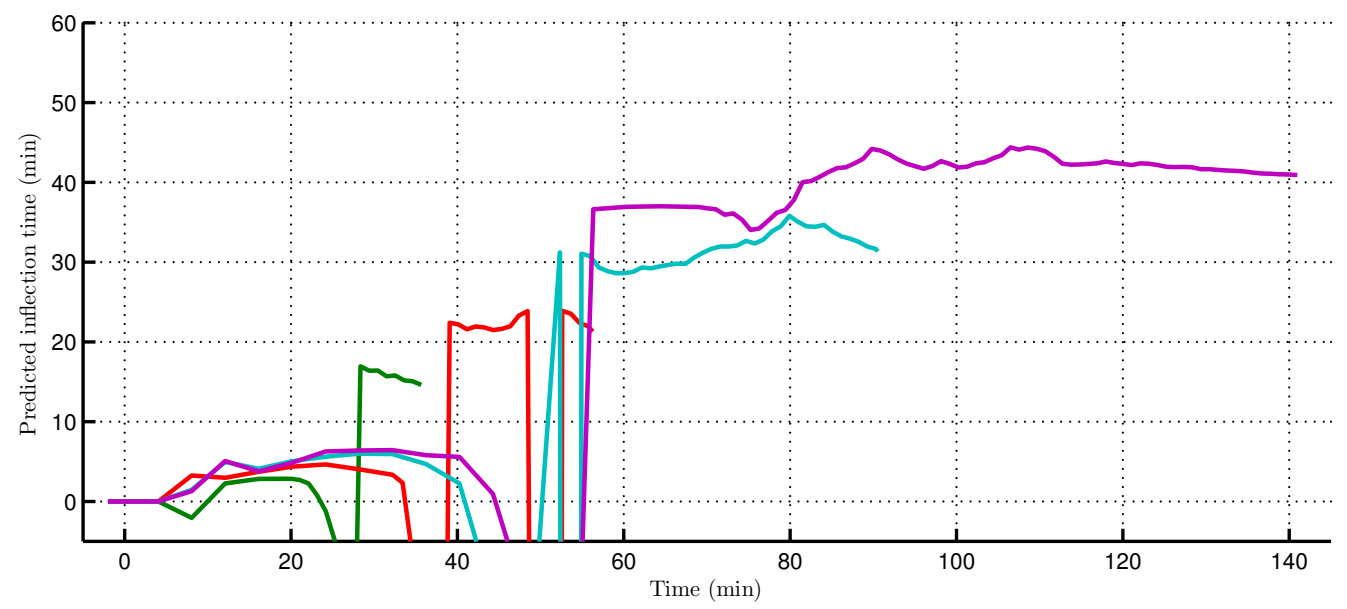

(b)

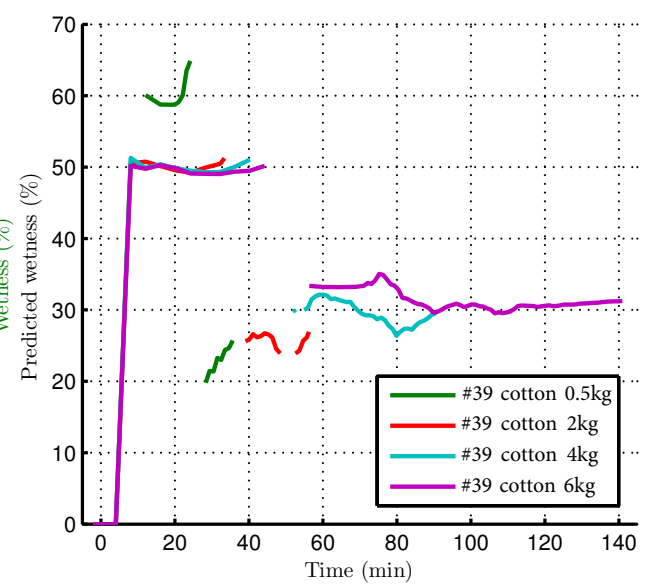




\section{Estimation of model parameters}

Sections 2 and 3 use data-driven models to analyse the drying process in the system. It is desirable that a deterministic model be developed to independently investigate the physics of drying. Although there was not much progress during MINZ on this problem, physical parameters necessary for such models were identified and studied. In this section we illustrate how experimental data may be used to find empirical parameters for use in a deterministic drying process model. Mass and energy balance equations describe the clothes drying process. The emphasis of this section is the determination of parameters in the mass balance equation. Table 1 lists variables and parameters.

A previous lumped-reaction engineering approach [3] treated evaporation as a chemical reaction process using zero-order kinetics with activation energy. In this section we use this kind of strategy to model the overall drying rate for the entire process.

The clothes drying process is considered to be water vapour transfer out of a porous solid. The clothing is modelled as a thermally thin material where the surface temperature is approximately the same as the material interior temperature.

The mass balance equation for the drying rate of clothes is [4]

$$
m_{c} \frac{d X}{d t}=-h_{m} A\left[\exp \left(\frac{-\Delta E_{v}}{\mathcal{R} T_{c}}\right) \rho_{v, \text { sat }}\left(T_{c}\right)-\rho_{v, a}\left(T_{a}\right)\right] .
$$

This equation is to be solved numerically to predict the moisture content, $\mathrm{X}$, of the clothes at a given time, $t$. Then, once the moisture in the clothes is determined to be below a pre-determined threshold, $X_{\mathrm{T}}$, the dryer is stopped and the clothes considered dry. To proceed we require the mass $m_{c}$ and the quantities on the right-hand side of the equation.

In practice, the theory of Section 3 or some other method can be used to approximate the load mass. The temperatures of the drying air and of the 


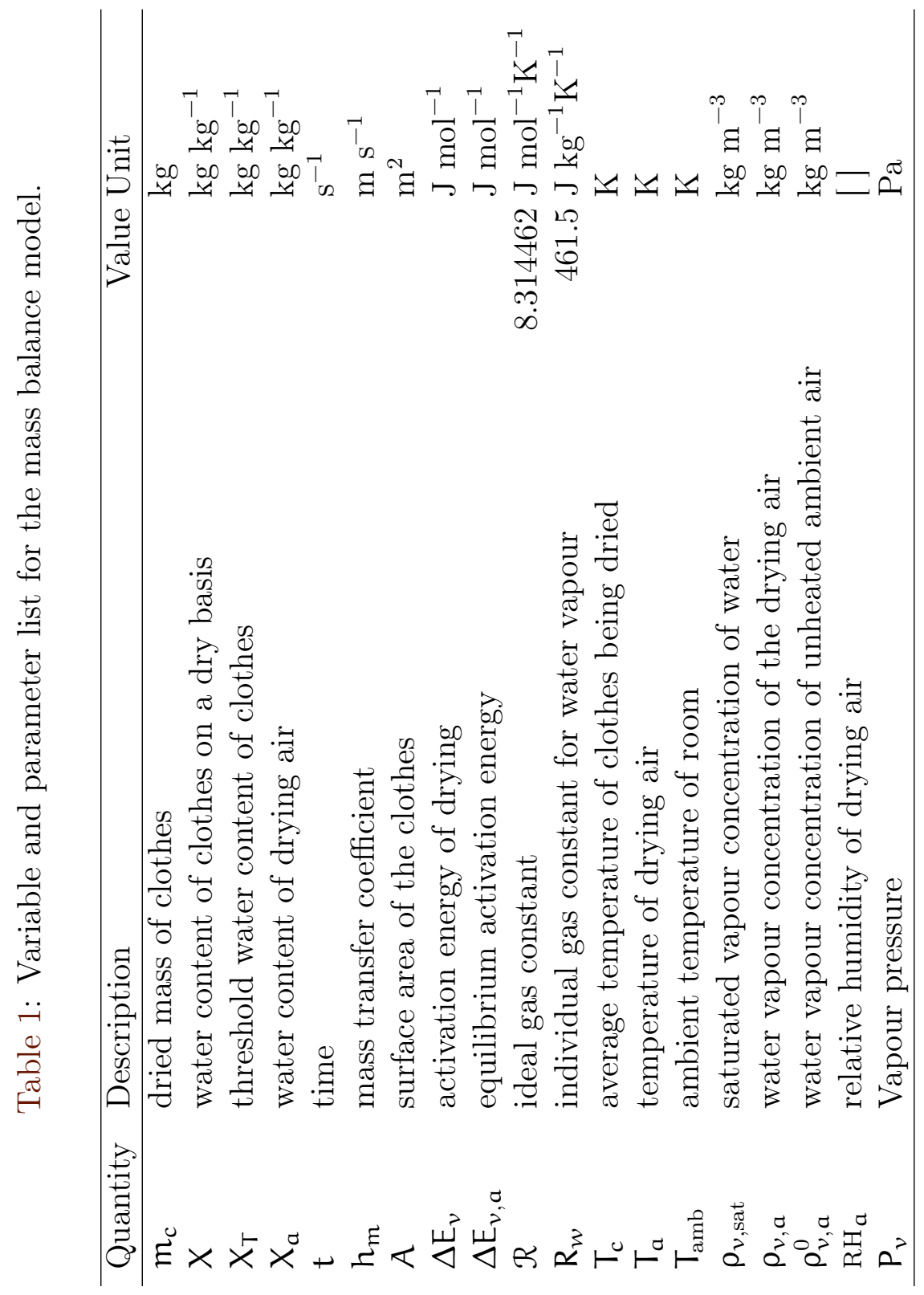


clothes can be measured using a set of thermocouples (which is how the test data were obtained). In the range $273 \mathrm{~K}$ to $473 \mathrm{~K}\left(0^{\circ} \mathrm{C}\right.$ to $\left.200^{\circ} \mathrm{C}\right)$, the saturated vapour concentration is approximated by [5]

$$
\begin{aligned}
& \rho_{v, \text { sat }}(T)=4.844 \cdot 10^{-9}(\mathrm{~T}-273)^{4}-1.4807 \cdot 10^{-7}(\mathrm{~T}-273)^{3} \\
& +2.6572 \cdot 10^{-5}(\mathrm{~T}-273)^{2}-4.8613 \cdot 10^{-5}(\mathrm{~T}-273)+8.342 \cdot 10^{-3} \mathrm{~kg} \mathrm{~m}^{-3} .
\end{aligned}
$$

The vapour concentration of the drying air could be determined by adding a humidity sensor at the dryer inlet, thus determining the relative humidity of the room. Then thermodynamics would dictate the vapour concentration as the air is heated. This is further discussed by Subsection 4.1.

The mass transfer coefficient $h_{m}=0.137 \mathrm{~m} \mathrm{~s}^{-1}$ for wool [6]. We expect cotton to be of similar order. An estimation of the surface area of the clothes was provided by Fisher and Paykel using an area per unit mass estimate,

$$
A \approx 27.79 \mathrm{~m}^{2}
$$

for the dry mass of clothes $\mathrm{m}_{\mathrm{c}}=5.558 \mathrm{~kg}$.

The activation energy, $\Delta \mathrm{E}_{v}$, is a measure of the difficulty in removing water from the clothes. $\Delta \mathrm{E}_{v}$ is expected to be dependent on the type of clothing in the machine and the water content in the clothes, $X$, relative to the water content of the drying air, $X_{a}$. When the water content, $X$, is large, the amount of energy per unit mole required to release water from the surface of the clothes is small. However, when the water content in the clothes is similar to the amount in the drying air, then there is a relatively large amount of energy required to further dry the clothes. The relationship between the activation energy (when normalised by the maximum it can attain under the given ambient conditions) and the moisture content has previously been fitted to a variety of curves $[3,7,8,9]$. Here we pursue the function $\Delta E_{v}=f\left(X-X_{a}\right)$ by analysing the $6 \mathrm{~kg}$ cotton drying data provided by Fisher and Paykel. Once $\Delta \mathrm{E}_{v}=\mathrm{f}\left(\mathrm{X}-\mathrm{X}_{\mathrm{a}}\right)$ is found then this is used to solve ODE (2) for any given cotton load size and estimate the drying time for that load. Similar 
calculations with different experimental data would be required for other load types such as a mixture of clothing materials.

\subsection{Experimental determination of the activation energy for a cotton load}

In order to determine the activation energy $\Delta E_{v}$ as a function of the water content, we use the experimental data for the cotton $6 \mathrm{~kg}$ load and rearrange ODE (2) for the activation energy:

$$
\Delta \mathrm{E}_{v}=-\mathcal{R} \mathrm{T}_{\mathrm{c}} \ln \left\{\left[-\mathrm{m}_{\mathrm{c}} \frac{\mathrm{dX}}{\mathrm{dt}} \frac{1}{h_{\mathrm{m}} A}+\rho_{v, \mathrm{a}}\left(\mathrm{T}_{\mathrm{a}}\right)\right] \frac{1}{\rho_{v, \text { sat }}\left(\mathrm{T}_{\mathrm{c}}\right)}\right\} .
$$

Figure 9 displays the experimental drying data, the moisture content, $\mathrm{X}$, as a function of time, $t$, together with a fitted polynomial equation

$$
X=-2 \cdot 10^{-16} t^{4}+5 \cdot 10^{-12} t^{3}-3 \cdot 10^{-8} t^{2}-4 \cdot 10^{-5} t+0.5007 \mathrm{~kg} \mathrm{~kg}^{-1} \text {. }
$$

This polynomial equation is differentiated to obtain

$$
\mathrm{dX} / \mathrm{dt}=-8 \cdot 10^{-16} \mathrm{t}^{3}+15 \cdot 10^{-12} \mathrm{t}^{2}-6 \cdot 10^{-8} \mathrm{t}-4 \cdot 10^{-5} \mathrm{~kg} \mathrm{~kg}^{-1} \mathrm{~s}^{-1} .
$$

This derivative is used in Equation (4) for the particular $6 \mathrm{~kg}$ cotton load with a given initial moisture content. However, for the application to other load masses and different moisture content of clothes, the moisture content dependence of the activation energy must be determined. Let $\Delta \mathrm{E}_{v, \mathrm{a}}$ be the equilibrium activation energy, defined as the maximum that the activation energy, $\Delta \mathrm{E}_{v}$, can attain under the given ambient conditions (temperature, humidity). Then [4]

$$
\Delta \mathrm{E}_{v, \mathrm{a}}=-\mathcal{R} \mathrm{T}_{\mathrm{a}} \ln \left(\mathrm{RH}_{\mathrm{a}}\right),
$$

where the relative humidity of the drying air is defined by

$$
\mathrm{RH}_{\mathrm{a}}=\rho_{v, \mathrm{a}} / \rho_{v, \mathrm{sat}}\left(\mathrm{T}_{\mathrm{a}}\right),
$$


Figure 9: Moisture content $\mathrm{X}$ of clothing load ' $\# 36$ cotton $6 \mathrm{~kg}$ ' over time $\mathrm{t}$.

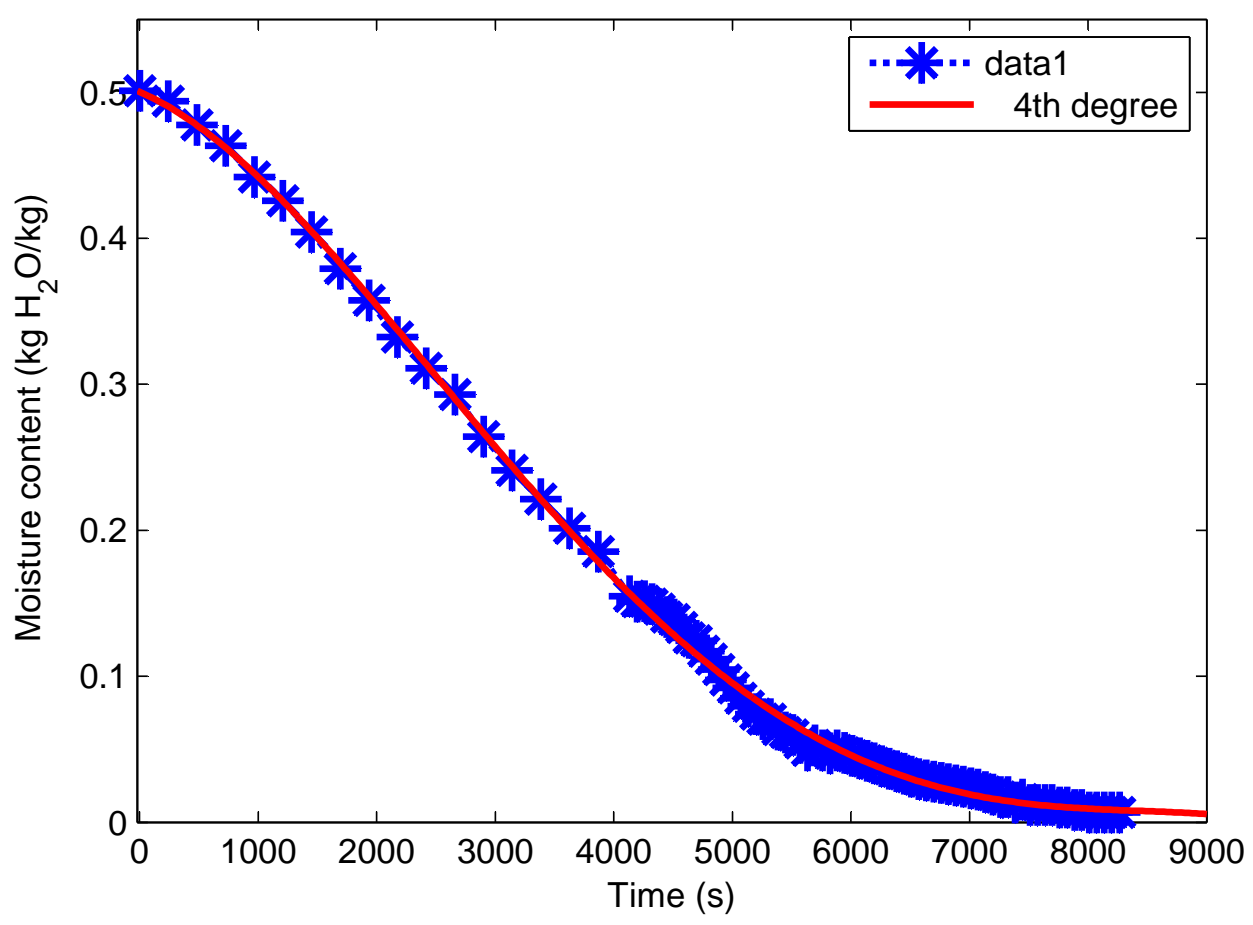

with $\rho_{v \text {,sat }}\left(T_{\mathbf{a}}\right)$ defined by (3). The relative humidity of the room itself was measured as $\mathrm{RH}_{\mathrm{a}}=0.6$ in the Fisher and Paykel experiments. As in previous reaction engineering models $[3,7,8,9]$, we seek a function, $\xi$, of the form

$$
\Delta \mathrm{E}_{v} / \Delta \mathrm{E}_{v, \mathrm{a}}=\xi\left(\mathrm{X}-\mathrm{X}_{\mathrm{a}}\right) .
$$

A temperature relationship is required for the vapour concentration of the drying air, $\rho_{v, \mathrm{a}}$. Assuming that the ideal gas law is a good approximation for the drying air, and that the pressure of the air does not change by much during the heating process (from the data, the pressure change is estimated to be less than $1 \%$ ), we estimate $\rho_{v, \mathrm{a}}$. 
Before heating, the drying air is at ambient (room) temperature. Given that we measure the relative humidity of the room, we express the initial vapour concentration of the drying air as

$$
\rho_{v, \mathrm{a}}^{0}=\mathrm{RH}_{\mathrm{a}} \rho_{v, \mathrm{sat}}\left(\mathrm{T}_{\mathrm{amb}}\right) .
$$

The ideal gas law states

$$
\rho_{v, \mathrm{a}}=\frac{\mathrm{P}_{v}}{\mathrm{R}_{w} \mathrm{~T}_{\mathrm{a}}},
$$

where $P_{v}$ is the water vapour pressure and $R_{w}=461.5 \mathrm{~J} \mathrm{~kg}^{-1} \mathrm{~K}^{-1}$ is the individual gas constant for water vapour. Assuming that the ratio $P_{v} / R_{w}$ is constant, then we find $\rho_{v, a}$ for a given temperature change by applying the ideal gas law.

Finally, from the experimental data provided by Fisher and Paykel for a $6 \mathrm{~kg}$ cotton load, we calculate $\Delta \mathrm{E}_{v}$ using Equation (4), normalise it by $\Delta \mathrm{E}_{v, \mathrm{a}}$, Equation (7), and plot the result versus the moisture content minus the air moisture content, $X-X_{a}\left(X_{a}\right.$ was calculated as $\left.\approx 0.01\right)$. The resulting plot is shown in Figure 10 with a fitted polynomial function

$$
\begin{aligned}
\Delta \mathrm{E}_{v} / \Delta \mathrm{E}_{v, \mathrm{a}}= & 2.2 \cdot 10^{4}\left(\mathrm{X}-\mathrm{X}_{\mathrm{a}}\right)^{8}-5.6 \cdot 10^{4}\left(\mathrm{X}-\mathrm{X}_{\mathrm{a}}\right)^{7} \\
& +6.1 \cdot 10^{4}\left(\mathrm{X}-\mathrm{X}_{\mathrm{a}}\right)^{6}-3.6 \cdot 10^{4}\left(\mathrm{X}-\mathrm{X}_{\mathrm{a}}\right)^{5} \\
& +1.3 \cdot 10^{4}\left(\mathrm{X}-\mathrm{X}_{\mathrm{a}}\right)^{4}-2.8 \cdot 10^{3}\left(\mathrm{X}-\mathrm{X}_{\mathrm{a}}\right)^{3} \\
& +3.9 \cdot 10^{2}\left(\mathrm{X}-\mathrm{X}_{\mathrm{a}}\right)^{2}-32 \cdot\left(\mathrm{X}-\mathrm{X}_{\mathrm{a}}\right)
\end{aligned}
$$

In theory, such a fitted function is multiplied by $\Delta \mathrm{E}_{v, \mathrm{a}}$ (Equation (7)) for the current ambient conditions, to determine the activation energy $\Delta \mathrm{E}_{v}$ at a given moisture content $X$ for use in the mass transfer equation (2). When used, along with the other discussed parameters, this would allow the estimation of the drying time for use with any mass of clothes. 
Figure 10: The normalised activation energy as a function of moisture content for the $6 \mathrm{~kg}$ cotton load data.

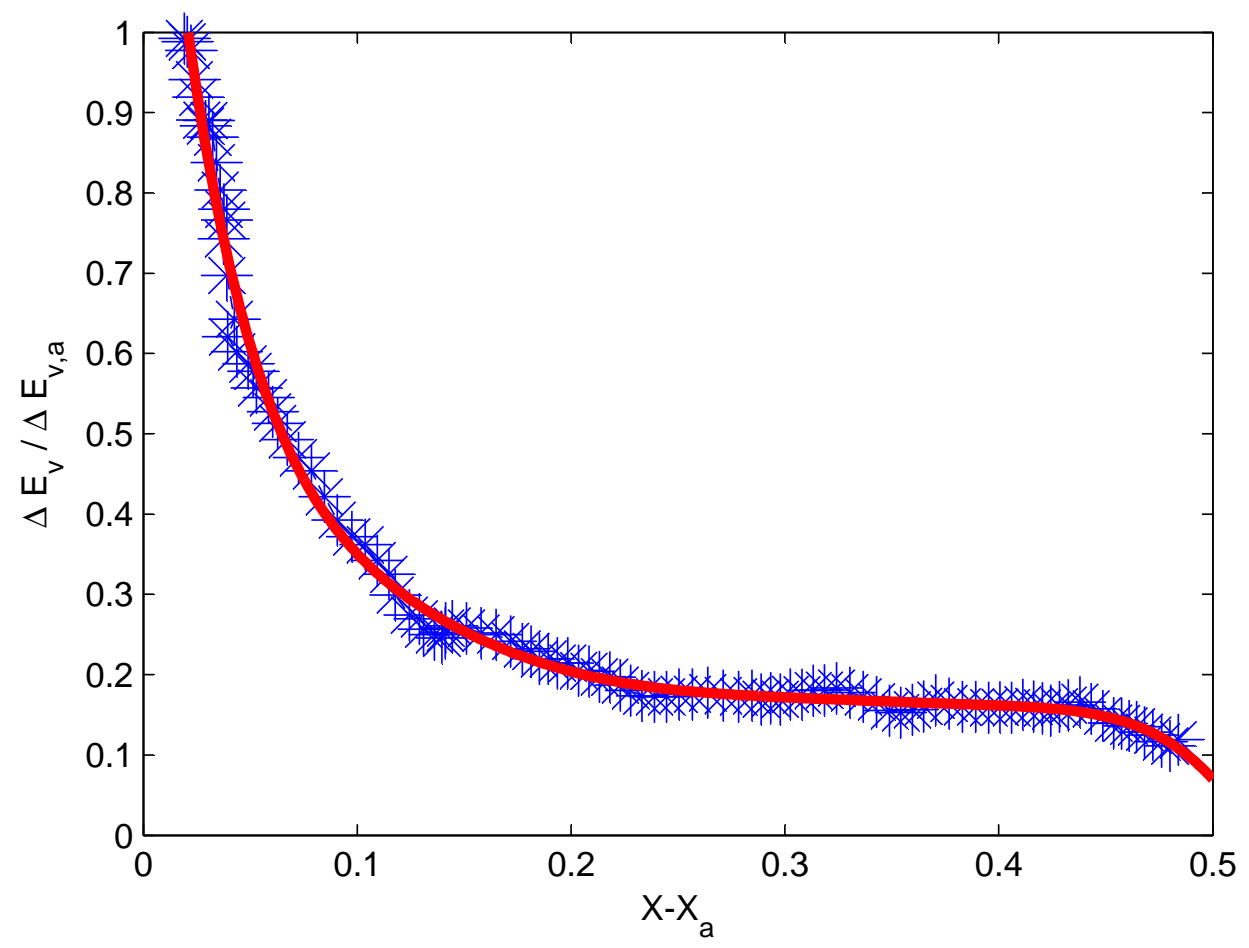

\section{$5 \quad$ Discussion and conclusions}

We investigated the drying process in a domestic clothes dryer. Current dryer models suffer from early cut-offs due to the simplicity of the data analysis. We introduced a simple stochastic method. This utilises a locally calculated regression model and an analysis of the variance to produce a confidence interval. Section 2 showed that the regression model is a good fit through analysis of the residuals, and that an improved termination policy could be implemented which defines cut-off when both the measured temperature and 
lower confidence limit pass a pre-defined threshold. A further advantage of this method was that it is simple and cheap (in the sense of required resource) which, given the limited processing power in the dryer, is essential.

Furthermore, in Section 3, a locally fitted fourth-order polynomial was used to determine the point of inflection which characterises every temperature curve. Practically, this regression fitting could be the same as is used in the stochastic model, leading to further computational efficiency. The point of inflection was of interest because it was noted (Subsection 3.1) that this point occurred at approximately the same moisture content, regardless of clothes mass. We hypothesise that this point may be used to relate one temperature curve to another, and may possibly lead to an estimation of time-to-go in the drying process.

Finally, in Section 4, we used experimental data to estimate a key physical parameter, the activation energy as a function of moisture content, which may be used in a future deterministic mathematical model.

Acknowledgements We are grateful to the Fisher and Paykel industry representatives James Smejlis, Stephen Kent, Ian McGill and Alim Guy for bringing this problem to MINZ 2015 and for their valuable input. We also acknowledge and thank the other team members who worked on the problem for their contribution: Maria Bruna, Saima Gul, Aroon Parshotam, Daniel Playne, Jairaj Promrak, Dimetre Triadis, Yousuf Tufail, Faheem Zaidi, Raziye Zarre. The organisation and hospitality at Massey University was greatly appreciated.

\section{References}

[1] C. Marsh and A. Wilkins, Determining temperature control of wash water in a laundry environment. Proceedings of the 2005 mathematics-in-industry study group 163-208, 2005. M239 
[2] C. Marsh, S. Taylor, P. Milliken and G. Senaratne, Developing an understanding of washing machine dynamics. Proceedings of the 2006 mathematics-in-industry study group 133-152, 2007. M239

[3] X. D. Chen, The basics of a reaction engineering approach to modeling air-drying of small droplets or thin-layer materials Drying Technology 26, 627-639, 2008. doi:10.1080/07373930802045908 M257, M259, M261

[4] X. D. Chen and A. Putranto, Modelling Drying Processes: A Reaction Engineering Approach, Cambridge University Press, 2013. ISBN 978-1-107-01210-3 doi:10.1017/cbo9780511997846 M257, M260

[5] R. B. Keey, Drying of Loose and Particulate Materials, Hemisphere Publishing Corporation, 1992. ISBN 0-89116-878-8 doi:10.1080/07373939208916507 M259

[6] A. K. Haghi, Heat \& Mass Transfer in Textiles. WSEAS Press, 2011. ISBN 978-1-61804-025-1 M259

[7] A. Putranto, X. D. Chen, S. Devahastin, Z. Xiao, and P. A. Webley, Application of the reaction engineering approach (rea) for modeling intermittent drying under time-varying humidity and temperature. Chemical Engineering Science, 66(10):2149-2156, 2011. doi:10.1016/j.ces.2011.02.025 M259, M261

[8] A. Putranto, X. D. Chen, and P. A. Webley, Modeling of drying of food materials with thickness of several centimeters by the reaction engineering approach (rea). Drying Technology, 29(8):961-973, 2011. doi:10.1080/07373937.2011.557793 M259, M261

[9] A. Putranto, X. D. Chen, Z. Xiao, and P. A. Webley, Modeling of high-temperature treatment of wood using the reaction engineering approach (rea). Bioresource technology, 102(10):6214-6220, 2011. doi:10.1016/j.biortech.2011.02.053 M259, M261 


\section{Author addresses}

1. Luke Fullard, Institute of Fundamental Sciences, Massey University, Palmerston North, NEW ZEALAND.

mailto:l.fullard@massey.ac.nz

2. Winston L. Sweatman, Centre for Mathematics in Industry, Institute of Natural and Mathematical Sciences, Massey University, Auckland, New ZEALAND.

mailto:w.sweatman@massey.ac.nz

3. Matt Wilkins, Institute of Fundamental Sciences, Massey University, Palmerston North, NEW ZEALAND. mailto:m.c.wilkins@massey .ac.nz

4. John Cater, Department of Engineering Science, University of Auckland, NEw ZEALAND. mailto: j.cater@auckland.ac.nz

5. Celia Kueh, SEAT, Massey University, Palmerston North, NEW ZEALAND.

mailto:c.s.l.kueh@massey.ac.nz

6. June Lau, Department of Statistics, University of Auckland, NEw ZEALAND.

mailto: june.lau@auckland.ac.nz

7. Tet Chuan Lee, Department of Engineering Science, University of Auckland, New Zealand.

mailto:tc.lee@auckland.ac.nz

8. Alexander Van-Brunt, Research Institute in Mathematical Sciences, Kyoto University, JAPAN.

mailto:alexvb@kurims.kyoto-u.ac.jp

9. Yuancheng Wang, Institute of Fundamental Sciences, Massey University, Palmerston North, New Zealand. 
mailto:wyc532@gmail.com 